\title{
ACOMPANHANDO MICROPOLÍTICAS JUVENIS: ESTRATÉGIAS
} CLÍNICO-INSTITUCIONAIS

\author{
ACCOMPANING YOUTHFUL MICROPOLITICS: A CLINIC \\ INSTITUCIONAL STRATEGY
}

\author{
Gislei Domingas Romanzini Lazzarotto, Júlia Dutra de Carvalho e Julia Lângaro Becker
}

Universidade Federal do Rio Grande do Sul, Porto Alegre/RS, Brasil

\begin{abstract}
RESUMO
O Acompanhamento Juvenil (AJ) é proposto no âmbito da prática da psicologia em extensão acadêmica no contexto de políticas públicas. Configura-se como uma prática, inspirada no Acompanhamento Terapêutico (AT), que busca estar com jovens para pensar a infração e o abandono nos processos de institucionalização vividos em medidas socioeducativa e protetiva. O exercício de construção com jovens de novas relações com a cidade evidencia o AJ como uma prática de análise das relações juvenis na rede que compõe as políticas públicas. Para tal tarefa, o diálogo com a pesquisa-intervenção e a esquizoanálise indicou três ferramentas conceituais: experimentar, escrever e cartografar. Os modos de escrever, produzidos pela equipe da psicologia através de um diário coletivo, enunciam a experimentação de percursos geográficos e existências e a análise de acompanhados e acompanhantes. Assim, emerge o AJ como uma estratégia de intervenção clínica e institucional na intervenção juvenil.
\end{abstract}

Palavras-chave: acompanhamento juvenil; acompanhamento terapêutico; psicologia; políticas públicas.

\begin{abstract}
This study propounds the Youthful Accompaniment (YA) in the ambit of psychology practices, arising from academic extension experiences in public politics. This practice is being taken as work strategy, inspired in another methodology called Therapeutic Accompaniment (TA), and brings the idea to be with young to think the youthful involvement with abandoning and infraction in institutional contexts. The construction of new relations with the city shows how the YA can give visibility to youth movements and your effects into institutional nets - in public politics context. A dialogue with intervention research and esquizoanalyse had shown us three conceptual tools: the experimenting, the writing and the cartography. The ways to write, produced by the psychology team, through a collective diary, announces experimentations produced in existential and geographic territories and in involved people's analyses. In this way, the YA becomes a clinical and institutional intervention strategy which works with youthful politics.
\end{abstract}

Keywords: youthful accompaniment; therapeutic accompaniment; psychology; public politics.

\section{Introdução}

As práticas da psicologia em contextos juvenis que propomos analisar fazem parte do projeto de extensão ESTAÇÃO PSI do Departamento de Psicologia Social e Institucional, na Universidade Federal do Rio Grande do Sul (UFRGS). O ESTAÇÃO PSI é formado por um grupo de estudantes e docentes com o objetivo de desenvolver atividades de extensão universitária, em psicologia social, orientadas pela análise institucional para intervir com as políticas juvenis. Dentre algumas ações da equipe está um Programa de Trabalho Educativo existente desde 2002 que se configura num convênio entre a UFRGS, uma organização pública federal e instituições da rede executora de medidas socioeducativa ${ }^{1}$ e protetiva $^{2}$ - FASE (Fundação de Assistência Socioeducativa), FPE (Fundação de Proteção Especial) e PEMSE/ FASC (Programa Municipal de Execução de Medidas Socioeducativas em meio aberto).

No referido programa, a Organização Pública Federal oferece um estágio em trabalho educativo para jovens entre 16 e 18 anos que passam ou passaram por processo de institucionalização nesses contextos de medidas. Essa iniciativa é desenvolvida com uma concepção que associa o estágio ${ }^{3}$ com a noção de 
trabalho educativo ${ }^{4}$, conforme Artigo 68 do Estatuto da Criança e do Adolescente - ECA (Lei n. 8.069, 1990), oferecendo atividades de aprendizagem laboral em setores administrativos. O procedimento central que sustenta a proposta é um convênio com as organizações executoras de medidas socioeducativa e de proteção que encaminham os adolescentes ao Programa. Enquanto servidores públicos orientam jovens no desenvolvimento de suas funções laborais dentro dos setores da Organização Pública Federal, a equipe do Grupo ESTAÇÃO PSI analisa as demandas desses servidores, de jovens e de técnicos das organizações executoras de medidas, acompanhando os percursos juvenis que se produzem nesse contexto.

No diálogo com Deleuze e Guattari (1997), situamos que esse Programa emerge de relações que compõe uma política pública juvenil. Há uma micropolítica operando no encontro com uma macropolítica formada de configurações estatais (organizações que compõe o convênio e a proposta), diretrizes educacionais (Lei de Estágios), formas de financiamento (bolsa-auxílio), corpos jurídicos de medidas socioeducativas e de proteção (ECA). A micropolítica movimenta as relações e produz práticas que fazem engrenar o que não estava previsto nas diretrizes de trabalho desses servidores, ou na forma de operar leis nessa organização para acolher jovens institucionalizados. Essa variação, que emerge do encontro macro e micropolítico, molar e molecular, ganha consistência a partir dos diálogos entre jovens e servidores, que do estranhamento com os novos lugares ocupados (de estágio e de orientação) enunciam um encontro de aprendizagens. O Programa se forma nessa relação de aliança que marca um novo território no contexto organizacional, pois tanto acolhe jovens como movimenta as práticas instituídas e os modos de subjetivar nas relações juvenis.

De certa forma, o Programa faz emergir um "não lugar". Se por um lado o Órgão Público Federal extrapola suas funções previstas, por outro as organizações envolvidas, que encaminham o público juvenil, sustentam essa outra possibilidade de trabalhar com o abandono e a infração. Conforme afirmam Deleuze e Guattari (1997), temos um agenciamento. Um agenciamento maquínico que conecta elos entre as leis, diretrizes, jovens, profissionais, ferramentas, fazendo funcionar uma proposta de trabalho educativo juvenil. E um agenciamento coletivo de enunciação que faz ecoar, entre os discursos de afirmação da cidadania e de saberes que prescrevem o Programa, as vozes de uma produção social encarnada em corpos juvenis como infração e abandono. Vozes juvenis que passam a ser problematizadas e dão passagem para outros sentidos nas práticas desenvolvidas.

Nessa perspectiva, o grupo ESTAÇÃO PSI também compõe esse agenciamento e, como linha que tece uma política universitária, propõe uma análise compartilhada das ações realizadas com a comunidade, problematizando as relações macropolíticas e micropolíticas, conforme as práticas de pesquisaintervenção. Orientamos-nos por Aguiar e Rocha (2007) que pensam a produção de conhecimento como uma ação que busca a interferência coletiva na produção de micropolíticas, tendo a experiência como uma positividade que produz a pesquisa na intervenção. Conforme destacam as autoras, tomamos o princípio da pesquisa-intervenção como um modo de produzir conhecimento, buscando investigar a vida de coletividades na sua diversidade numa intervenção clínica e institucional. Assim, a extensão se produz como saber que, no diálogo com outros saberes, afirma um modo de construir ações públicas, viabilizando a construção de espaços de problematização coletiva junto às práticas de formação e de pesquisa.

Nessa experiência, foram sendo enunciadas questões que eram discutidas entre jovens, servidores públicos e equipe de psicologia, algo próprio das movimentações da enunciação num agenciamento. Por vezes essas problematizações extrapolavam os limites estabelecidos: estar em local de estágio e estar cumprindo medida socioeducativa e de proteção. Insistia em nosso fazer o movimento de pensar com esse público juvenil como se davam suas escolhas entre as lógicas institucionais que regravam suas vidas. Para esse exercício do pensamento alguns espaços construídos com a psicologia eram privilegiados (grupo dispositivo de jovens, reuniões com servidores, atendimento individual); outros, inusitados, pois se davam no encontro em um elevador do prédio público, na visita ao núcleo residencial de abrigagem e ao centro de internação, ou mesmo na rua.

Esses movimentos nos levaram a compreender que ali havia um singular pedido de acompanhamento, um suporte possível para a vivência do que se colocava como um aprendizado do desconhecido. O que seria esse desconhecido? Na experiência nesses contextos, encontramos uma tendência a evidenciar a necessidade da autonomia juvenil. Necessidade também de que esse jovem e essa jovem, seja pela idade, seja pelo cumprimento da medida ou seja ainda pelo que se espera socialmente dele e dela, tem que se vestir de uma autonomia que afirme a busca de uma vida adulta. Por outro lado, a institucionalização vivida nas medidas se orienta por marcas que impelem a cumprir ações definidas por saberes jurídicos, pedagógicos, 
psicológicos, operados em práticas institucionais. Pouco se pensa com eles e elas sobre a apropriação de seus processos. O que estão se tornando na tessitura dessas práticas e experiências parece não figurar como importante durante as medidas. A análise e a pretensa decisão sobre seu percurso ficam a cargo daqueles que executam as medidas. Jovens com autonomia, adultos, quiçá cidadãos? É esse o desconhecido que identificamos como demanda de análise a ser compartilhada com o público juvenil em questão. Portanto, a questão que orienta este artigo enuncia o movimento de estar com eles e elas, percorrendo os lugares e os modos de subjetivar que vão sendo produzidos entre saberes e práticas institucionais. Esse estar com do qual nos referimos é um termo trazido por Lazzarotto (2009) que diz daquilo que se compõe em zonas de vizinhança de territórios existenciais e que se afirma em alianças a serem construídas na experiência ética e política de modos de viver, conforme abordamos no decorrer do artigo.

Ainda sobre a autonomia, fomos percebendo que as vias do trabalho e da educação tendem a assumir um lugar de regulação de um "problema social", conforme analisam Sposito e Carrano (2003). Os véus de uma infração social evocada como "problema da juventude" justifica programas para ocupar jovens que emergem como um problema na sociedade brasileira. Assim, a institucionalização que se dá pelas medidas pode manter sua função de controle através do "cumprimento" da escolarização e do preparo para o trabalho. Nesse movimento, não são analisados os modos de subjetivar associados aos modos de trabalhar e educar, nem são exploradas as possibilidades de aprendizagens de si com o outro, para que o jovem exercite suas escolhas nessas condições que operam as políticas.

Diante dessas questões, fomos desenvolvendo uma atenção aos modos como nossos saberes e análises operavam as práticas com essas políticas. Se por um lado estávamos trabalhando com adolescentes, pois nosso público possuía a idade a partir dos 16 anos; por outro, seguíamos com a passagem pelos 18 anos. Fomos fazendo a escolha pelo termo jovem-juvenil, pois pensamos que a polissemia dessa enunciação nos remete a problematizar mais os modos de ser e subjetivar, construídos nesse momento histórico, do que apenas nos situar num segmento de idade. Nesse sentido, Bocco (2006, p. 53) propõe pensar a juventude não na direção da individualização - nem da massificação, mas como um "plano vital sem início, término ou duração predeterminados que consiste em uma inquietação com o mundo, um inconformismo com o status quo e uma força propulsora de mudanças". Tal plano não estaria atrelado a uma etapa de vida, tratando-se de uma linha que pode atravessar a todos e qualquer um durante sua existência. Partindo dessas questões optamos em nossas pesquisas pelos termos "jovem" e "juvenil".

Para nós, percorrer as análises e as ações em rede, agenciadas a partir de um programa de trabalho educativo juvenil, implicou em estar na vida da cidade organizada por conexões de equipamentos públicos nos quais jovens circulam e se subjetivam. Ao pensarmos as relações entre o Acompanhamento Terapêutico e os modos de trabalhar com jovens fomos mapeando um "como fazer" que passamos a territorializar como Acompanhamento Juvenil (AJ), uma estratégia de intervenção clínica e institucional. Os relatos de experiências singulares que revisitamos ao longo do artigo formam um corpo de análise que dá visibilidade para a importância desse modo específico de acompanhar, o qual propomos como uma variação do AT. Optamos por problematizar essa experiência, pois consideramos estratégico darmos forma a outros modos de praticar a psicologia nos contextos de execução de medidas socioeducativa e protetiva, possibilitando que outras experiências dessa natureza dialoguem com essa linha de produção de conhecimento que se propõe ética e política nas in(ter) venções juvenis. Enquanto análise de experiências com o AJ, priorizamos, neste artigo, a discussão de situações que dizem respeito ao contexto de medidas socioeducativas.

\section{Diálogos entre AT e AJ: uma inspiração e uma variação}

O Acompanhamento Terapêutico (AT) surge num contexto da reforma psiquiátrica como uma modalidade clínica que abre novas possibilidades no trabalho com a clínica das psicoses. Essa nova estratégia vem conectar espaços institucionais a lugares públicos, fazendo pontos de articulação e de contato entre os eles a partir de um exercício de circulação pela cidade e do consequente engajamento no espaço e tempo social. É por isso que o AT ocupa uma função importante no tratamento de condições psíquicas peculiares como as de um psicótico (Palombini et al., 2004).

É dessa articulação da clínica com a cidade que vem nossa inspiração de tomar o Acompanhamento Terapêutico como referencial para orientar as práticas de acompanhamento com jovens. Utilizarse do espaço público e movimentar-se pelo urbano nos fez perceber que estávamos construindo outra modalidade dessa prática clínica. O diálogo com AT abriu possibilidades para afirmar essas práticas de circulações com jovens como um modo de intervir, 
como uma possibilidade de acesso ao jovem (acesso dele ao nosso trabalho e de nosso trabalho a ele). A estratégia de ir além das fronteiras institucionalizadas em práticas definidas na geografia de lugares como do estágio, do cumprimento da medida, do abrigo, da escola, entre outros; e, respectivamente, em cada um desses lugares um orientador, um juiz, um técnico, um professor. Entre lugares e funções, a vida juvenil vai sendo marcada pelas práticas institucionalizadas que se infiltram nos modos de subjetivação como repertórios a serem correspondidos. E suas vontades por onde andavam?

Nossas práticas, então, foram ocorrendo no exercício de seguir o movimento de cada jovem à medida que situações iam se apresentando. Um olhar atento ao que acontecia com este ou aquele jovem diante da exigência de um atestado de frequência escolar, quando tudo indicava que já não havia ida a escola e disso dependia sua permanência no estágio; ou de uma solicitação de segunda via de um registro de identificação, o que demandava ir a uma delegacia, envolvendo um contato policial marcado nessa história juvenil como ameaça. Sutilezas percorridas pelo olhar e pela escuta daquilo que vai além da justificativa de um dia após o outro: "mais um dia e eu resolvo, dona". Uma tarefa tão simples: um atestado de frequência ou um registro de perda de documentos para obter a segunda via. Mas, tal tarefa dizia de um processo em curso, no qual estava o movimento de percorrer sua relação com esses lugares, das marcas institucionalizadas de quem não deu certo nessa escola, ou de quem se relaciona com a polícia na expectativa de ser preso. Outros sentidos poderiam ser produzidos nessas relações juvenis e institucionais? Para tal, percebemos que era preciso ir à rua, percorrer trajetos e desvios, indagar possibilidades de outros caminhos, e talvez fazer de "mais um dia e eu resolvo" o tempo de viver o acontecimento sem estar só para "resolver".

As aproximações entre o AT e o AJ pela via ética do trabalho ficavam evidentes, assim como a prática do acompanhar se coloca em ambos como uma ação política. O que tomamos do AT para afirmar o AJ é justamente essa possibilidade de flexibilizar as relações nas quais os processos de subjetivação se constituem para acompanhados e acompanhantes. O dilema de "resolver" não se colocava apenas para estes e estas jovens, também permeava o dia a dia de quem os atendia nas diferentes funções e de quem estava munido de quais saberes disciplinares. Assim, ao intervirmos com as situações de institucionalização, a circulação pela cidade e a entrada em outros espaços, exercitamos uma ética de trabalhar compondo zonas de vizinhança para potencializar novas relações com o urbano, com os saberes e com o exercício de formas de ser no mundo.

Como pensamos a diferença entre esses modos de acompanhar? O AT, conforme visto anteriormente, nasce de uma política contextualizada na reforma psiquiátrica, num sentido que afirma a luta antimanicomial. Por isso, ele se propõe a uma clínica diferenciada no âmbito, originalmente, da psicose, e que foi sendo alargada, conforme aborda Lancetti (2006), considerando outros modos de sofrimento psíquico configurados no contemporâneo. A ampliação dessas solicitações é configurada no âmbito da rede de atenção em saúde mental, bem como analisada no âmbito das discussões das psicopatologias. Pensamos que é importante apontar as variações que esse modo de trabalhar tem construído e que vão adentrando outros contextos e produções de demanda. Assim, passamos a problematizar as relações intersetoriais das políticas de saúde e as peculiaridades do atendimento ao público em medidas socieducativas e de proteção.

Em diálogo com a concepção de sujeito de direito proposta pelo ECA (Lei n. 8.069, 1990), temos as diretrizes em saúde mental infanto-juvenil (Ministério da Saúde, 2005) que indicam a noção de responsabilidade, o direito ao cuidado e a singularidade, problematizando as práticas orientadas por uma forma homogênea e indiferenciada. $O$ princípio de nosso acompanhar implica em estar atento ao que se diz desses jovens como substituto de sua própria palavra, o que implica que as demandas formuladas por outros sejam ouvidas como demandas juvenis; e ainda que a análise dessa demanda seja tomada por um discurso naturalizado, que enuncia mais uma adaptação de jovens e profissionais ao funcionamento institucionalizado, do que propriamente uma análise de demanda.

Nessa perspectiva, o AJ ganha sua relevância exatamente por encontrar-se com a espeficidade de um público juvenil nas entranhas das produções sociais no contemporâneo. No trabalho que fizemos com jovens, percebemos que a relação da juventude com a cidade já se encontrava transbordante. A demanda juvenil de transitar em diferentes territórios levou a psicologia de carona nesse movimento, acompanhando a necessidade de estar de modo diferente em lugares nos quais se vê e é visto como "aquele" da infração e/ou da proteção. Estar em lugares diferentes e estar diferente nos lugares que já se esteve para movimentar as relações que subjetivam jovens e para movimentar quem com eles se relacionam nesses percursos institucionais. Pensamos que é pela condição juvenil insistente e insurgente que as forças de regulação da sociedade tomam a potência juvenil como problema, demandando uma correção 
desse problema no indivíduo. Assim, passamos a direcionar nossa análise ao contexto de produção dessa demanda, discutindo a produção social da violência e como as práticas da psicologia e de cumprimento da medida ainda reproduzem a institucionalização de vidas em segmentos que devem ser atendidos sem fazer funcionar a rede entre políticas públicas.

Optamos por tomar a potência juvenil como lugar problemático de algo a fazer. Nesse sentido, assegurar uma nomeação, como variação do AT, diz da natureza do regime de práticas que temos cartografado: um acompanhamento que se faz da potencia juvenil, AJ. Sob essa perspectiva, persistimos na condição de indagar nossas práticas e de estarmos atentos às invenções e atualizações metodológicas desse percurso.

\section{Ferramentas de um modo de acompanhar clínico-institucional}

Abordamos a noção de ferramenta a partir da pista lançada por Gilles Deleuze em diálogo com Michel Foucault, no que se tornou o texto "Os intelectuais e o poder", na obra Microfísica do Poder (Foucault, 1979): "Uma teoria é como uma caixa de ferramenta. Nada tem a ver com o significante... É preciso que sirva, é preciso que funcione" (p.71). Para "fazer funcionar" nossa caixa de ferramentas levamos em nossos percursos de acompanhamento três verbos: experimentar, escrever e cartografar.

Experimentar, conforme análises de Deleuze e Parnet (1998), implica estarmos sensíveis ao que acontece na rede sempre aberta da multiplicidade de modos de ser. A multiplicidade constituise como um campo de possíveis para uma problematização daquilo que escapa ao prescrito e tensiona nossa prática. Esses autores afirmam que os experimentadores tomam como fio condutor a exterioridade das relações que forçam o pensamento a pensar aquilo que repugna o próprio pensamento. Assim, identificamos que não bastava entregar-se à experiência de acompanhar os percursos juvenis, era preciso construir um modo de estar com na experimentação da diferença nas relações juvenis. "Com" é uma preposição que liga partes, estabelece relações e diz daquilo que se compõe em zonas de vizinhança do que fomos mantendo em tensão entre territórios geográficos e existenciais de jovens e seus percursos. "Estar", verbo no infinitivo, para deixar em aberto como vamos conjugar o encontro num momento e num lugar que se faz na aliança entre acompanhados e acompanhantes, saberes e instituições, políticas. Portanto, não diz apenas do estar com quem acompanhamos, mas do agenciamento do qual fazemos parte.

A tensão que emerge nessas relações é um sinalizador desse movimento processual operando as tendências da multiplicidade que nos constitui e que busca expressão. Podemos manter essa experimentação ao escrever, pois ao escrevermos, analisam Deleuze e Parnet (1998), inventamos agenciamentos a partir de agenciamentos que nos inventaram. Trata-se da enunciação do que vai constituindo nossos modos de ser, indicando possíveis percursos de processos de subjetivação. Na escrita estão as palavras de ordem que, segundo analisam Deleuze e Guattari (1995), remetem aos comandos e a todos os atos que estão ligados aos enunciados por uma obrigação social, mas ali também estão as passagens de um devir minoritário, a diferença. A mesma palavra tem essa dupla natureza: "é preciso extrair uma da outra - transformar as composições de ordem em componentes de passagens" (Deleuze \& Guattari, 1995, p. 59). Ao escrevermos mantemos o processo de experimentar a tensão de nossas práticas com jovens e expressamos variações que se fazem desse encontro.

Deleuze e Guattari (1995) evidenciam o caráter coletivo e político da linguagem à medida que ela deixa de ser apenas um sistema de representação para tornar-se uma prática que exprime uma língua própria ao contexto em que se produz. Assim, a cartografia dos percursos vividos com jovens vai sendo atualizada na escrita, que tanto mantém a constância e a reprodução do que se diz, como dá passagem à variação que faz surgir novas distinções em nossos ditos. O que promove essas condições de expressão ao escrever é a abertura para viver a diferença que emerge nas relações que compomos no trajeto de intervir. A pragmática desse escrever em intervenções institucionais ocorreu com o uso de uma lista de discussão, em ambiente a distância pela equipe de psicologia do Grupo ESTAÇÃO PSI, a qual veio a constituir um "diário coletivo", conforme propõe Lazzarotto (2009). O "diário coletivo" funciona através de uma rede de convivência em uma lista de discussão que propicia aos seus participantes o exercício de suas vozes com a escrita. Esse escrever dá materialidade às vozes dos participantes, constituindo uma enunciação de práticas e configurando um modo próprio de expressão que traz a fala de si e de quem compõe o fazer psi. O "diário coletivo" acolhe o que se vive através do movimento de escrever mensagens, elaboradas em qualquer tempo e lugar pelos participantes da equipe de psicologia. Uma escrita com livre acesso do grupo que o utiliza e que acolhe as práticas na eminência dos acontecimentos, conforme possibilita a ferramenta em rede. Ao escrever se dá o movimento de compartilhar o que está acontecendo consigo (pelo próprio ato de 
escrever) e com a equipe (que se constitui como um leitor-escritor que segue o movimento de escrever em desdobramentos de mensagens-respostas).

Aconjugação desse diário coletivo com os espaços presenciais de seminário dessa equipe de psicologia construiu uma pragmática do escrever dos modos de acompanhar-analisar os processos de subjetivação juvenis e as lógicas institucionais. Uma produção coletiva à medida que práticas, tecnologia e uma rede de relações macropolíticas e micropolíticas passavam a dar forma a um modo próprio de intervir-pesquisar e de acompanhar as demandas juvenis. Deleuze e Parnet (1998) enfatizam que manter a heterogeneidade dos modos de ser envolve falar com, escrever com: com o mundo, com uma porção do mundo, com pessoas. Os autores afirmam que não se escreve pelo outro ou do outro. Escrevemos daquilo que agenciamos entre um e outro na tentativa de manter o fluxo de um processo onde a vida prolifera. Essa é nossa direção ao propormos um modo de cartografar e constituir um diário coletivo que compõe um agenciamento coletivo de enunciação.

Com os verbos "experimentar" e "escrever" fomos cartografando os percursos vividos no acompanhamento com jovens. Estar no processo e cartografar esse movimento indicava um encontro no qual estávamos atentas à multiplicidade que nos produzia nessa prática e às conexões que nos agenciavam com indivíduos, potências, políticas, micropolíticas. Como tratamos de relações juvenis e institucionais, destacamos que instituição e subjetivação são dobras de um plano social. Dessa forma,

os modos de subjetivação não são considerados como frutos de um sujeito que mergulha em sua interioridade, mas como invenções de um coletivo constituído nos agenciamentos do viver, isto é, os sujeitos e as instituições são vistos como efeitos, resultados dos jogos entre os encontros, entre formas e forças que habitam o mundo. (Oliveira \& Fonseca, 2007, p. 133)

A feitura do diário coletivo pela equipe de psicologia tornou-se uma condição para compor a estratégia clínico-institucional do acompanhar. Ao escrevermos enunciamos o que nos afeta e os modos como essa afetação compõe o trabalho da equipe. Para nós, esse movimento de cartografar com a escrita criou outro regime de visibilidade da passagem de sentidos entres as prescrições de nossas práticas, compondo o diálogo de um modo de acompanhar na variação com o Acompanhamento Terapêutico (AT). São essas escritas que aqui retornam configurando um estilo próprio, o qual se vincula ao processo de atualização dessas práticas quando produzimos uma cartografia para compartilhar conhecimento. Os percursos aqui enunciados são práticas de análise produzidas no Diário Coletivo Estação Psi, no período de 2008 e 2009, priorizando situações relativas ao contexto de medidas socioeducativas.

\section{Uma clínica-institucional para acompanhar percursos juvenis}

Ao seguirmos na produção desse modo de acompanhar juvenil, chegamos a momentos de angústia, nos quais não sabíamos o que fazer com os pedidos, as denúncias e, no limite, as vidas. Algo nos dizia efetivamente que precisávamos retornar para a rede de execução de medida para sabermos o que fazer. Era o "como" que nos movimentava. Tínhamos sido fisgadas. Como efeito, tínhamos a afirmação de novos territórios, geográficos e existenciais, e a construção de outros sentidos a cada caminhada. Um encontro marcado pelo acaso também era elemento a compor a ferramenta clínica de se perceber no mundo. Um acaso que só acontecia por estarmos abertos à experimentação de acompanhar intensidades da micropolítica juvenil.

Nas ruas de Porto Alegre, sem horário ou local marcado, também se davam encontros e paradas para conversar com jovens egressos do Programa já referido. Dessas paradas iam sendo construídos diálogos e perguntas que passaram a nos alimentar e a nos forçar para que prosseguíssemos nessa experimentação com jovens: O que desejam? O que podem? O que solicitam? Nesse sentido, as andanças com esse público juvenil possibilitavam a experiência na sua multiplicidade, e nossas práticas passaram a se dar sob essa interferência. Percebemos que, ao utilizar o espaço da cidade enquanto oportunidade e experimentação em circulações diferentes, produzíamos com cada jovem outra forma de falar de si, de se perceber e de ser percebido no contato com quem compõe as organizações em rede.

Entre as distintas situações desse nosso andar, escrevemos aqui com as passagens de um tempo que permanece sendo enunciado em nós, em estilos que dizem de percursos vividos e contados. Quando o escrever se dá na eminência de uma prática na tensão entre a prescrição e o acontecer, estamos produzindo mais um dos movimentos do acompanhamento. A enunciação de algo que se produz no processo de afetar e ser afetado numa escrita compartilhada. Não nos centramos na análise do autor, do acompanhante, do acompanhado, do técnico ou da equipe, mas no mapa de práticas que emergem nessa enunciação coletiva. 


\section{Andança da fuga: o percurso solicita liberdade, os saberes dizem não}

Rich (nome fictício) esperava a audiência que mudaria sua situação de medida socioeducativa de privação de liberdade para liberdade assistida (modalidade que permite cumprir a medida em liberdade, tendo acompanhamento técnico periódico). Ele se encontrava numa modalidade de medida que possibilitava atividades externas (ICPAE- Internação Com Possibilidade de Atividade Externa), condição que lhe dava possibilidade de participar do Programa de estágio em trabalho educativo. Esse jovem impressionava por sua desenvoltura para ir e vir ao circular na cidade, muitas vezes causando situações que extrapolavam certas regras estabelecidas pela organização executora de medidas. Alongava os tempos de trajeto do local de internação até o local de estágio e vice-versa para andar pela cidade e viver o tempo de "liberdade". A equipe técnica que o acompanhava percebia como indicado à Liberdade Assistida, mas temia que se o jovem assim estivesse, poderia colocar tudo a perder, pois não cumpriria a termo as combinações, considerando seus usos do tempo. Por isso, a equipe optou por indicar a continuidade da modalidade ICPAE, com a justificativa de mantê-lo protegido e evitar que ele não conseguisse terminar de cumprir o tempo de medida determinado. Mantida a medida de internação, o jovem reagiu de modo distinto da expectativa da equipe técnica: passou a não retornar ao local de internação após os finais de semana em casa e no estágio, até que não retornou mais. Foi considerado em situação de fuga.

Sua solicitação de liberdade, apontada pelos atos de uso do tempo e discutida com ele no estágio, foi entendida apenas como não cumprimento da regra. Mas, ali estava a possibilidade de experimentar uma nova condição nessas relações, pois à medida que participava das análises sobre esse modo de agir, expressava os impasses gerados por esse outro modo de organizar a vida com a medida e com a expectativa da liberdade após a internação. No estágio, ele também exercitava esses movimentos com as regras de comportamento no trabalho, como poder ou não usar um boné e o modo de ser referido no crachá. Permanecer na medida de internação indicava, para as equipes, proteção e respeito às regras, para o jovem, descrédito na sua capacidade de exercitar a autonomia e desrespeito a sua relação com o próprio corpo. A atitude de fuga do jovem provocou a análise com as equipes envolvidas: Por que apostar que o exercício do jovem com as regras diz necessariamente de um modo de reprodução da infração? Por que não olhar para os movimentos que este jovem, entre conflitos, solicitava a aposta em sua capacidade de agir fora do local de internação?

No acompanhamento, ele compartilhou a decepção que teve ao perceber que a aposta que se tinha nele não considerava seu querer. A partir de sua fuga da medida e do estágio, esse jovem manteve encontros de acompanhamento, alguns planejados através de ligações telefônicas que ele nos fazia, outros ao acaso na rua. Além de acolher essa busca do jovem para falar de como vivia esses percursos nas ruas da cidade, ou ainda de suas idas e vindas com um familiar, acionamos as organizações envolvidas nesse percurso institucional implicado com o jovem. Algumas vezes nossa sensação era de que, agora, os saberes nada tinham a dizer, estavam institucionalizados nos territórios circunscritos pelos muros das organizações que habitavam. $\mathrm{O}$ jovem permanecia na rua.

\section{Andança do livro: uma visita, uma história, um diagnóstico}

Novamente entrávamos num Centro de Internação Socioeducativa. Passamos por grades na expectativa de ver Ulisses. Durante seu percurso no estágio, ele propiciou dois movimentos que evidenciavam as relações institucionais. Um primeiro no qual pede para ser internado novamente, pois tinha medo de estar na rua e em sua moradia. Um segundo, quando retorna para o Programa e compartilha seus impasses com o desenrolar da medida. Entre essas andanças, realizamos uma visita ao local de internação. Na sala de visitas, ele apareceu com mãos atadas a ferro, nas costas. Mãos que carregavam uma história, pois estavam agarradas no livro Elite da Tropa, um empréstimo nosso. E é de histórias que ele fala durante nossa visita. Contou dos percursos dele, de outros e do livro. Livro que leu, de que gostou, mas que não o fez desistir de entrar para o batalhão de operações especiais (para ele, o BOPE é a legalização da violência). Livro que circulou pelas mãos dele, de outros jovens, de trabalhadores que o acompanhavam na medida. Circulação que lembra a que ele nos conta dele mesmo, a de passar pelas mãos da mãe, do pai, da polícia, de projetos, de monitores, de técnicos. Ulisses reacende em nós a história do livro e, principalmente, de seu pedaço de vida e de sua angústia. Vida e angústia que fica em nós. Nossa história também se cria ali. Verdades dele próprio e verdades nossas falando de muitos tipos de violência. E é nesse percurso violento que Ulisses produz esculturas delicadas de origami, as quais nos entrega nessa visita como presentes. Uma delas é um pássaro grande, pronto para voar, como libertado da inércia 
do papel que agora se dobra e produz vida. Tempo da visita esgotado.

Na saída, conversamos com uma técnica, que nos pergunta se não consideramos Ulisses um sedutor e dissimulado. A preocupação buscava a confirmação do que ele era. Não havia perguntas quanto aos seus diferentes percursos, entre os quais solicitar a própria internação. Ficamos a pensar em como os saberes vão sendo impregnados pelas paredes que circundam territórios de vida e passam a sustentar essas paredes. Terminada a visita, produz-se em nós a vontade de derrubar paredes. Não por vitimizar ou culpar alguém, mas por perceber que a violenta dureza que vibrava em Ulisses, vibrava na técnica e vibrava em nós. Saímos da casa de internação querendo nela entrar mais.

O modo de acompanhar evidenciou tensões que agenciaram a vontade das acompanhantes de realizar ações dentro da organização que opera a medida de privação de liberdade. Afetações de uma visita que produz vontades à medida que estávamos sensíveis aos trajetos que foram sendo traçados. Nesse percurso, a tensão, conforme propõe Lazzarotto (2009), pode ser tomada como um incômodo, constituindo uma imobilidade no/do fazer. Isso acontece quando a tensão vivida em nossas ações é identificada apenas como efeito reprodutor de um regime de práticas naturalizado. Entretanto, se entendermos esse incômodo como produtor de pensamento, situamos a tensão como sinal de experimentação que desestabiliza nossas práticas. Tensão que nos ensina a escutar os percalços institucionais e que os coloca como o próprio objeto do nosso trabalho.

O movimento de análise do que se produzia no percurso juvenil enunciava que os lugares oferecidos pelas práticas institucionais para acolher os atos juvenis eram insuficientes. Havia uma institucionalização de práticas orientadas mais pelas palavras de ordem, do que pelo que esses enunciados dizem de um singular percurso juvenil. Seguir a linha que traçava a possibilidade de outros territórios em construção tornou-se, para nós, a alternativa a seguir. A continuidade da análise dessas práticas no diário coletivo fez durar o movimento disparado pela potência juvenil que solicitava escuta. Assim, fomos evidenciando o exercício de análise experimentado pelo acompanhante, pois à medida que este mapeia as condições em que se produzem as subjetivações juvenis, vive também as afetações de seus modos de viver e de suas escolhas neste acompanhar.

Esse exercício, clínico e institucional, ético e político, possibilitou dar continuidade às ações de circulação juvenis e de diálogo com profissionais da rede para provocar a percepção de outros lugares produzidos nessa relação. Exercícios como: perceber que o jovem volta ao serviço no qual cumpriu a medida para contar sobre seu estágio aos monitores ou técnicos; discutir o conteúdo de um livro que fala da violência que nos produz nestas relações; inventar do acompanhamento que se fez a partir do controle, uma atitude de testemunho e de aliança para movimentar escolhas. Quando um jovem percebe naquele que o acompanha uma diferença de olhar, inscrevese uma possibilidade de ensaiar outra história de "vir a ser" entre ambos. A clínica passa a ser feita também de uma ida à escola com o jovem para reativar sua matrícula e para cartografarmos tanto o medo da professora e o lugar de ameaça assumido pelo jovem, como a afirmação de que é no trajeto da vida que outros sentidos podem ser convocados para a intervenção. Assim, podemos analisar que sentido teria a finalização de uma medida socioeducativa cumprida por um jovem, se as relações deste jovem e da prática escolar permanecem orientadas pela ameaça. A questão que formulamos com o AJ enuncia que acompanhar é uma tarefa orientada pelo princípio da multiplicidade que compõe os modos de ser juvenis, e pelo princípio inventivo que produz as práticas institucionais.

\section{Um regime de praticar: acompanhar $\mathrm{COM}$ jovens}

Desde o início de nosso trabalho no Programa, questionamo-nos sobre como deveria ser para estes e estas jovens (participantes do Programa) viverem no embate entre lógicas institucionais: a do trabalho, a da educação, a jurídica. As linhas divisórias formavam e deformavam-se à medida que escutávamos mais e mais os modos juvenis. Em suas trajetórias singulares construíam relações de responsabilidade, cooperação e abertura para falar de si em contraposição com um lugar regido pelo controle do cumprimento da medida socioeducativa. O estágio passou a constituir-se como um lugar de diálogo sobre os modos de trabalharaprender com essas relações juvenis, em que jovens e equipes passaram a analisar a função desse Programa e da política pública que o sustentava. Optamos por percorrer a linha que criava tensão entre as lógicas institucionais, fazendo desse percurso a orientação para analisar os processos de subjetivação.

Dialogamos com Foucault (2003), que destaca as práticas como "alvo" - "ponto de ataque" - para construir as análises das problematizações que emergem no jogo de forças das relações institucionais. 
Sua hipótese é de que as práticas têm sua própria regularidade, sua lógica, sua evidência, sua estratégia. Portanto, é necessária a análise de como se criam esses regimes de práticas, para acionarmos outros modos de exercitá-las. Lugares de trabalho e lugares de cumprimento da medida que no encontro juvenil produzem ensaios com o que se deseja, com o que se gosta, com o que mais podemos. Para nós, equipe de psicologia, assim foi sendo formulada a estratégia de uma análise clínico-institucional.

Marcamos reuniões com a rede, ouvimos outras tantas vozes, seguimos em produções de trabalho conjunto com técnicos que operam as medidas. Observamos que essas práticas nem sempre podiam dar conta das questões daquele ou daquela jovem que nos fez o pedido, mas que efetivamente geravam processos de análise com equipes que reverberariam nas produções com outros jovens e na rede. Acompanhar é aceitar um convite produzido na demanda em análise e fazer dos deslocamentos das práticas com a psicologia uma possibilidade de aliança de acompanhantes e acompanhados. Enquanto profissionais de um saber, movimentamos lugares disciplinados e assumimos o percurso de acompanhante que é constantemente levado pelos devires do acompanhado. E, ainda assim, cabe a pergunta: Para que acompanhar, afinal? Seguimos com a escrita de uma de nós no Diário Coletivo Estação Psi de 2009.

Encontro Lian na rua. Nesse dia, ele estava com uma questão e queria muito conversar. Ele coloca sua questão:

Queria que tu me ajudasse com um jovem do meu bairro. Ele é guri muito bom, mas está andando com outros que são da pesada. Já falei com ele que iria com ele lá no MPF para te conhecer. Ele precisa trabalhar, e não sabe procurar emprego.

Diante de tal pedido me ponho à disposição. $\mathrm{O}$ acompanhado no dia marcado chega com dois jovens, e começamos o trabalho de pesquisar lugares de estágio e trabalhos disponíveis em sites e outros que eles poderiam acessar se tivessem um currículo, o qual nos propusemos a fazer juntos. $\mathrm{O}$ acompanhado fica durante todo o processo, fala sobre oportunidades existentes na busca de empregos e de outros projetos na rede de Porto Alegre. Lembra de alguns momentos em que nós dois procuramos emprego para ele e também lembra sobre a calma que é preciso ter quando se recebe um não em uma entrevista. Esse jovem cumpriu medida socioeducativa. Esse mesmo jovem, acompanhado há dois anos, tornou-se uma rede de apoio para outros jovens no seu bairro.

\section{Notas}

Conforme artigo 103 do Estatuto da Criança e do Adolescente (Lei n. 8.069, 1990), verificada a prática de ato infracional, será determinado pela autoridade competente medidas socioeducativas que, conforme o tipo de infração, envolve desde a advertência até internação com privação de liberdade. O caráter socioeducativo comporta aspectos coercitivos (responsabilização pelo ato infracional) e aspectos educativos (articulação de questões pedagógicas, terapêuticas e sociais).

2 Por falta, omissão ou abuso dos pais ou responsável o/a adolescente passa a residir em entidade sob responsabilidade do Estado, conforme artigos 98 e 101 do Estatuto da Criança e do Adolescente (Lei n. 8.069, 1990). O acompanhamento a essa realidade indica longa permanência de crianças e adolescentes nessas instituições, bem como dificuldades para uma organização autônoma após 18 anos, quando devem ser "desligados".

3 Conforme Lei n. 11.788 (2008), o estágio é um ato educativo escolar supervisionado, desenvolvido no ambiente de trabalho, que visa à preparação para o trabalho produtivo do educando que esteja frequentando o ensino regular. Nesta experiência, o estágio implica em quatro horas diárias, totalizando vinte horas semanais, com bolsa auxílio mensal e auxílio-transporte.

4 Conforme Artigo 68 do Estatuto da Criança e do Adolescente (Lei n. 8.069, 1990), o Trabalho Educativo compreende uma atividade laboral em que as exigências pedagógicas relativas ao desenvolvimento pessoal e social do educando prevalecem sobre o aspecto produtivo. No Programa referido as equipes dos setores que recebem e acompanham os jovens em trabalho educativo orientam atividades como arquivo, protocolo de processos, apoio à secretaria, recepção, almoxarifado; oferecem treinamento em informática e apoio escolar; fazem reuniões com técnicos e organizações das políticas públicas governamentais em função de situação decorrente do cumprimento de medida.

\section{Agradecimento}

Apoio e financiamento da PROREXT-UFRGS.

\section{Referências}

Aguiar, K. F. \& Rocha, M. L. (2007). Micropolítica e o exercício da pesquisa intervenção: referenciais e dispositivos em análise. Psicologia Ciência e Profissão, 27(4), 648-663.

Bocco, F. (2006). Cartografias da Infração Juvenil. Dissertação de Mestrado, Programa de Pós-Graduação em Psicologia, Universidade Federal Fluminense, Niterói, RJ.

Deleuze, G. \& Guattari, F. (1995). Mil Platôs: capitalismo e esquizofrenia (Vol. 2). Rio de Janeiro: Ed. 34.

Deleuze, G. \& Guattari, F. (1997). Mil Platôs: capitalismo e esquizofrenia (Vol. 4). Rio de Janeiro: Editora 34.

Deleuze, G. \& Parnet, C. (1998). Diálogos. São Paulo: Escuta.

Foucault, M. (1979). Microfísica do poder. Rio de Janeiro. Edições Graal. 
Foucault, M. (2003). Mesa-Redonda de 20 de Maio de 1978. In M. Foucault, Ditos e Escritos IV: estratégia, poder-saber (pp.334-351). Rio de Janeiro: Forense Universitária.

Lancetti, A. (2006). A amizade e o acompanhamento terapêutico. In R. G. Santos, Textos, texturas e tessituras no acompanhamento terapêutico (pp. 21-26). São Paulo: Instituto A Casa/ Editora Hucitec.

Lazzarotto, G. D. R. (2009). Pragmática de uma Língua Menor na formação em Psicologia: um diário coletivo e politicas juvenis. Tese de Doutorado, Programa de Pós-Graduação em Educação, Universidade Federal do Rio Grande do Sul, Porto Alegre.

Lei n. 8.069, de 13 de julho de 1990. (1990). Dispõe sobre o Estatuto da Criança e do Adolescente e dá outras providências. Acesso em 14 de fevereiro, 2014, em http:// www.planalto.gov.br/ccivil 03/leis/18069compilado.htm

Lei n. 11.788, de 25 de setembro de 2008. (2008). Dispõe sobre o Estágio de Estudantes. Acesso em 14 de fevereiro, 2014, em http://www.planalto.gov.br/ccivil_03/_ato20072010/2008/lei/111788.htm

Ministério da Saúde. Secretaria de Atenção a Saúde. Departamento de Ações Programáticas Estratégicas. (2005). Caminhos para uma Politica de Saúde mental infantojuvenil. Brasília: Autor.

Oliveira, A. M. \& Fonseca, T. M. G. (2007). Contribuições de Deleuze: o acontecimentalizar no social e as sinuosas linhas da trama institucional. PSICO, 38(2), 133-138.

Palombini, A. et al. (2004). Acompanhamento terapêutico na rede pública: a clínica em movimento. Porto Alegre: Editora da UFRGS.

Sposito, M. P. \& Carrano, P. C. R. (2003). Juventude e políticas públicas no Brasil. Revista Brasileira de Educação, 24, 1639.

Recebido em: 13/10/2009

Revisão em: 09/07/2010

Aceite em: 06/01/2012

Gislei Domingas Romanzini Lazzarotto é Psicóloga, Doutora em Educação, Professora da UFRGS, no Instituto de Psicologia do Departamento de Psicologia Social e Institucional e coordenadora do Grupo de Extensão

ESTAÇÃO PSI. Endereço: Instituto de Psicologia Departamento de Psicologia Social, Ramiro Barcelos, 2600 - sala 300-F, Bairro Santa Cecília. Porto Alegre/RS, Brasil. CEP 90035-003.

E-mail: gislei.ufrgs@gmail.com

Júlia Dutra de Carvalho é Psicóloga, Bacharel em Ciências Jurídicas e Sociais (PUCRS), Mestre em Psicologia Social e Institucional e doutoranda em Psicologia social e institucional pela UFRGS, atuando na área de saúde mental coletiva, pesquisadora no Grupo de Extensão ESTAÇÃO

PSI da UFRGS.

E-mail:juliadcarvalho@gmail.com

Julia Lângaro Becker é Psicóloga da Divisão de Atenção Psicossocial ao Servidor do Departamento de Atenção à Saúde da UFRGS, foi integrante do Grupo de Extensão ESTAÇÃO PSI da UFRGS. E-mail: julialbecker@gmail.com

\section{Como citar:}

Lazzarotto, G. D. R., Carvalho, J. D., \& Becker, J. L. (2013).Acompanhando micropolíticas juvenis: estratégias clínico-institucionais. Psicologia \& Sociedade, 25(n. spe. 2), 55-64. 